\title{
A reference open data vertical axis wind turbine, with individual pitch control, for code validation purposes
}

\author{
Ilmas Bayati*, Stefano Foletti, Davide Tarsitano, Marco Belloli \\ Politecnico di Milano, Dipartimento di Meccanica, Via La Masa 1, 20156, Milano, Italy
}

\begin{abstract}
This paper presents the features and capabilities of a vertical axis wind turbine (VAWT) designed and built by the authors, which is meant to be the reference machine for open data code validation purposes under the project VODCA, VAWT Open Data for Code Assessment. The machine, whose design details are provided openly and summarized in the present document, has Individual Pitch Control (IPC) capability and it will be used for wind tunnel tests. Related results will be shared with participants who want to validate their own code, in terms of prediction of the aerodynamics or assessment of IPC strategies. The article reports a comprehensive overview of the state of the art of laboratory tests for VAWTs as well as the motivation of VODCA project, further to the need of code validation against experimental tests in controlled environment. The various phases of the project are also presented. Furthermore, the design of the carbon fiber blades, the structural components, as well as the mechatronics of the machine are summarized in this paper. Moreover, the experimental characterization of the machine's effective capabilities and properties, carried out after the completion of the building process, is reported and then the testing possibilities are defined and discussed.
\end{abstract}

\section{Introduction}

The technology of vertical axis wind turbines (VAWTs) has been extensively studied in the 70's-90's [1], without taking off as effectively competitors of the more commercially accepted horizontal axis wind turbines (HAWTs).

Nevertheless, as wind energy is moving to deep offshore sites for exploiting higher quality wind resources as well as overcoming social acceptance related issues, VAWTs are recently being considered as potential alternative to HAWTs for floating offshore wind turbines (FOWTs) [2,3]. Among others [4], one of the main advantages of floating VAWTs is that the generator is placed at the base of the tower, rather than at hub height, with obvious enhancement on the stability of the floating system, bringing about smaller floaters and then reducing the overall costs of the system itself $[5,6]$. Therefore, the study of the technical aspects behind VAWTs and the feasibility of such a technology, especially for deep offshore applications, is living a revival through novel concept being recently considered, thanks to scientific and commercial

\footnotetext{
* Corresponding author.

E-mail address: ilmasandrea.bayati@polimi.it (I. Bayati).
}

partnerships (e.g. Spinfloat by EOLFI [7], Twinfloat by Nenuphar [8] or the FP7 funded project DeepWind [9]).

However, the aerodynamic efficiency of lift based VAWTs (i.e Darrieus) is lower than HAWTs in that the different working principle is characterized by inherently unsteady aerodynamics and distorted and time-dependant wake, which greatly affect the efficiency of the downwind sector of the machine, not to mention the efficiency of drag-based ones (i.e. Savonious) [10]. Furthermore, the variation of the angle of attack experienced by blades is much wider in VAWTs than in HAWTs [11], causing the airfoils to encounter dynamic stall $[12,13]$ during main shaft rotation, especially at low tip speed ratio (TSR), affecting also the self-starting capability of Darriues type VAWTs [14].

For these reasons, variable pitch concepts can potentially increase the overall performance of H-Darrieus types VAWTs, overcoming the self-starting issue and improving the low TSR working region $[15,16]$. A wide variety of possible different passive mechanisms for blade collective pitch control systems has been designed since the Darrieus' patent in 1931 [17], an extensive review of such mechanisms (e.g. camlinkage, inertial and aerodynamic force driven) can be found in Ref. [18]. More VAWTs with variable pitch were tested in small wind tunnels, either with passive systems [19-22] as well as some attempts with active ones [23], although 
still lacking an extensive investigation of the effect of different control strategies on various machine parameters.

In this scenario, the advanced numerical models aimed at predicting the complex aerodynamics and performance of VAWTs require verification, as well as validation against experimental data. In this regard, beside rare cases of verification, such as in Ref. [24], where a comparison among inviscid flow codes were carried out, no relevant contributions can be register for VAWTs; on the contrary, under international energy agency (IEA) tasks, remarkable code comparison experiences must be registered for horizontal axis offshore wind turbines (i.e. OC3 [25]). Regarding the numerical vs experimental validation, the continuations of OC3 project, OC4 [26] and OC5 [27] must be reported, concerning respectively ocean basin wind/wave tests on a semi-submersible floating HAWT and also with open ocean data. These projects ([25-27]) are characterized by openness, which provide useful specific modelling experience to many engineers and scientist, with an undoubtedly acceleration on findings and technological consequence.

Therefore, objective of this work is to present the structural, mechanical characteristics and control capabilities of an H-Darrieus vertical axis wind turbine with active individual pitch control (IPC), entirely developed at Politecnico di Milano. This prototype is meant to be a reference IPC-VAWTs for code validation, following the same openness philosophy as previous similar experiences ([25-27]). This open data project will be run under the name VODCA, which stands for VAWT Open Data for Code Assessment, as it will be explained more thoroughly in the next paragraph. Furthermore, in the following, the features of the facility, Politecnico di Milano Wind Tunnel, where wind tunnel tests under VODCA project will take place, are reported. VODCA project is meant to be a totally open project. PoliMi is going to sharing, starting from the current paper, all the detailed features and capabilities of the reference IPCVAWT, as well as wind tunnel results on the machine. Moreover, the authors will coordinate the benchmark by carrying out the comparison among the results of different participants' codes, welcoming master or PhD students to take part to the setting up, conduction and post-processing of the experimental activities, so that also the academic aspect is strengthened by the project, beside obvious industrial R\&D consequences.

\section{Open data purpose and VODCA project}

The VODCA project has been recently launched by the authors at the symposium "Scientific and Technological Challenges in Offshore Vertical Axis Wind Turbines" in Delft, The Netherlands (September 2016). Further information can be found on the website [28]. As previously mentioned, the main aspect of this project is the openness. VODCA project is developed over three phases, within two-years timeframe (although without time constraints):

- Phase I: Code-to-code comparison. In this phase, participants are asked to run simulations considering the presented PoliMi's machine as reference in specific working conditions, possibly the ones which are going to be adopted for experimental validation in the phase II. However, this phase is supposed to highlight the differences and capabilities of the various codes adopted by participants to assess the performance of VAWT (e.g. inviscid, CFD etc ...), with a thorough investigation of pros and cons of different modelling approaches, which, according to authors, has never been conducted so far on VAWT in a comprehensive manner.

- Phase II: numerical Vs experimental validation. This phase will take advantages by a first round of measurements in the low turbulence test section of Politencnico di Milano wind tunnel, whose characteristics are reported in the following. This first step of testing is supposed to provide sources for validation in fixed pitch condiand simple IPC control strategies. Therefore, the approach of this phase of validation is "bottom-up", in terms of complexity.

- Phase III: numerical Vs experimental validation, with focus on control. Following the experience and findings of phase II, this phase is focusing on the implementation of more advanced control strategies and wake measurements on the PoliMi machine.

New participants from academia and industry are continuously joining the project, contributing to the creation of an already consolidated research hub for VAWT promoting the next VODCA phases (e.g. IEA tasks, EU funded projects...).

\section{The facility}

The facility in which the PoliMi IPC VAWT is being tested is the Politecnico di Milano 1.4 MW closed loop wind tunnel, Fig. 1. It is composed of two test sections for different applications. An atmospheric boundary layer $(\mathrm{ABL})$ test section, $3.84 \times 13.84 \mathrm{~m}$, where the flow has $36 \mathrm{~m}$ to develop the desired wind profile and turbulence intensity (up to 25\%), generated by means of both passive (obstacles) or active generator, before hitting the model which is placed on a $13 \mathrm{~m}$ diameter turn table $\left(360^{\circ}\right)$, for investigating different incoming flow angles. Active turbulence generation is possible thanks to the independent control of each of 14 fans set in two rows array. The maximum wind speed that can be reached in this test section is $14 \mathrm{~m} / \mathrm{s}$ with less than $2 \%$ of turbulence intensity in smooth flow condition. In this test section, among different ABL applications (e.g. bridges, stadiums and buildings), also wind energy measurement campaigns have been carried in the last decade $[29,30]$.

In the $4 \times 3.84 \mathrm{~m}$ low turbulence test section, up to $55 \mathrm{~m} / \mathrm{s}$ wind speed with turbulence intensity less than $0.1 \%$ can be generated. Two different configurations can be adopted, closed and open jet (Fig. 2). The latter will be considered for testing the herein presented reference machine under VODCA project, as can be seen in Ref. [31]. Moreover, the high quality of the flow in terms of
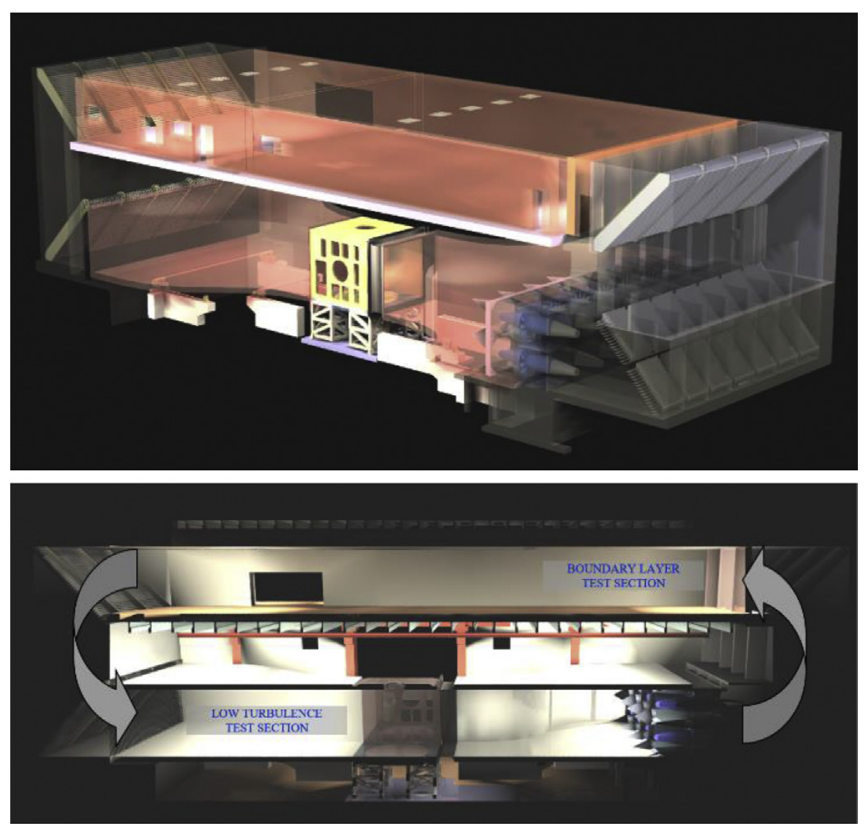

Fig. 1. Politecnico di Milano closed loop wind tunnel. 


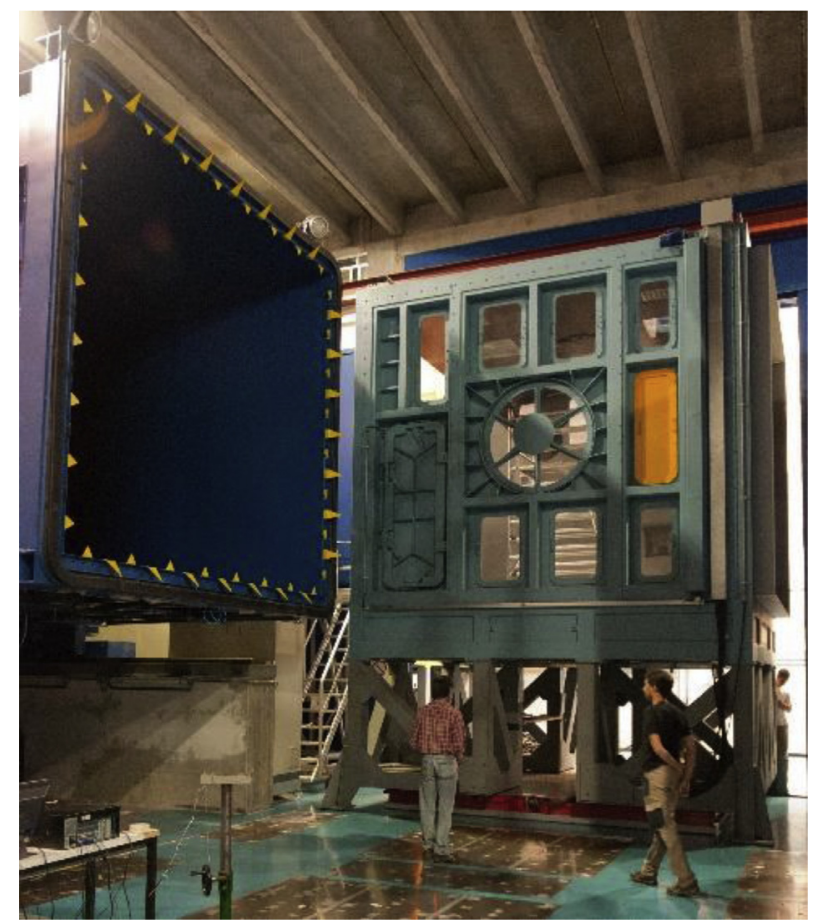

Fig. 2. Low turbulence test section of Politecnico di Milano wind tunnel in open jet configuration.

reproduction of closely free condition, which is not obvious in the open jet condition and with a rotor spinning as for VAWT, has been intensively investigated [32], providing satisfactory results. For the sake of clearness, in Fig. 3, the variation of the measured pressure coefficient, at mid height, as function of the distance $y$ from the center $(y=0)$ is reported and in the whole wind tunnel speed range. It can be observed that the negligible loss is found approximately up to $1700 \mathrm{~mm}$, which is consistent with rotor radius of the reference machine in the operational configuration $(R=1000 \mathrm{~mm}$, Fig. 4), as it will be reported in the following. For further distances from the center of the test section, the flow becomes wider, due to the absence of walls (open jet configuration), causing a drop of pressure coefficient. The presence of spinning rotor will inevitably

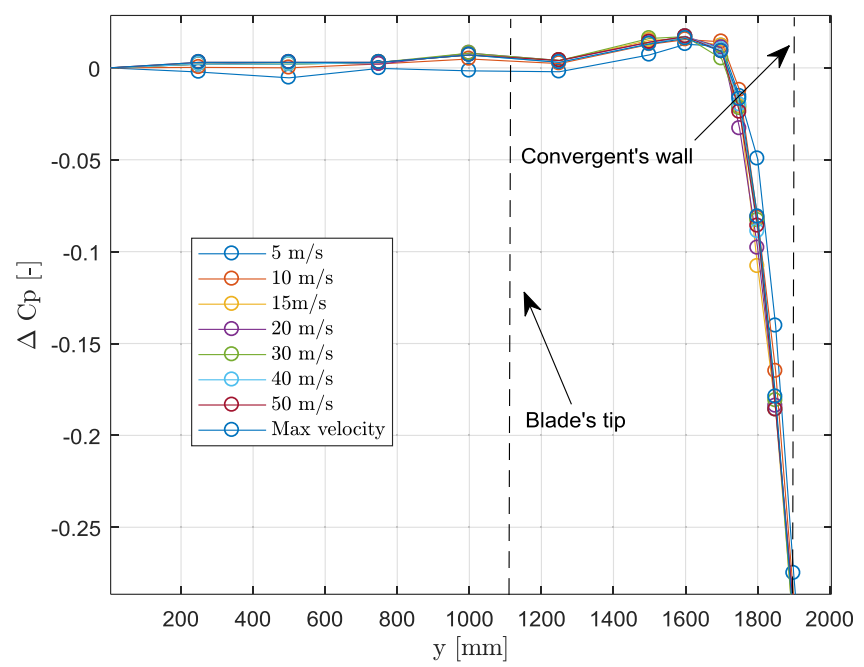

Fig. 3. Low turbulence test section: measured difference of pressure coefficient along $\Delta \mathrm{Cp}$, at mid height, as function of distance $\mathrm{y}$ from the center $(\mathrm{y}=0)$. cause an incoming flow deviation, nevertheless, quantifying this deviation for different operational conditions of the wind turbine being tested is not obvious. However, it is being investigated at the time of this paper, through a numerical and experimental approach.

\section{The design}

The PoliMi VAWT was dimensioned for Tip Speed Ratio ( $\lambda$ ) 4, and angular speed $(\omega) 300 \mathrm{rpm}(5 \mathrm{~Hz})$ of rotational speed and radius $\mathrm{R}=1.5 \mathrm{~m}$. It was originally designed for a different application, however it rapidly turned into VODCA project idea, as the international renewed attention to VAWTs was growing louder. Fig. 4 reports the overall dimension of the reference machine, the choice of the airfoil (four digits NACA 0021) and the chord length $C$ are justified in the following paragraph. Moreover, with reference to Fig. 4 , the solidity of the machine, which governs the aero-dynamics of VAWTs, defined as:

$\sigma=\frac{N C}{2 R}$

where $N$ is the number of blades and $R$ the rotor radius, has two different values. This is due to two possible radii $\mathrm{R}$ available, $1.5 \mathrm{~m}$ and $1 \mathrm{~m}$ for studying also the effect of different solidities as well as limiting the blockage effect and flow deviation in the wind tunnel open-jet configuration. This makes possible to test with two different solidity configurations.

The machine consists in carbon fiber blades, connected by means of twin braces, upon which aerodynamic fairings can be placed during the tests, to the hollow aluminium shaft, with external diameter of $200 \mathrm{~mm}$ and with sectional changes. This is connected in series to the main shaft motor and to rotary slip rings, which gathers all the input/output cables, passing through the hollow shafts. A main supporting steel structure, visible in Fig. 4, is placed upon a steel table so that the middle height of the rotor $(H / 2)$ coincides with the exact center of the open jet test section (Fig. 2). Being an IPC machine, each motor unit is placed at lower end of each blade, as explained in the following.

\subsection{Aerodynamics}

In order to get the aerodynamic forces for the structural design of the blades, the Double Multiple Stream Tube (DMS) code has been adopted [34], with the conventions reported in Fig. 5. Since the final aim is to implement different control strategies on the real machine, that were not a priori known during the design stage, an optimal control law was defined either to have a reference for the dynamic dimensioning of the blades and for the choice of the proper actuators. The optimal variation of the pitch angle $\varphi$ was found as to maximize the tangential force $F_{t}$, for each azimuthal angle $\vartheta$, both for upwind and downwind (Eqs. (2) and (3)). Since gradient-base optimization algorithms implied excessive computational effort, due to the number of possible combinations of pitch angles in the two sectors of the stream tube, a genetic algorithm (e.g. ga.m Matlab subroutine) was adopted.

$F_{t, t o t}\left(\vartheta, \varphi_{u}, \varphi_{d}\right)=F_{t}\left(\vartheta, \varphi_{u}\right)+F_{t}\left(-\vartheta, \varphi_{d}\right)$

$\max \left(F_{t, t o t}(\vartheta)\right)=F_{t, \text { tot }}\left(\vartheta, \varphi_{\text {opt }}(\vartheta)\right)$

Therefore, once defined the design dynamic conditions $(\lambda=4$, $\omega=300 \mathrm{rpm})$ and the azimuthal discretization $\left(\Delta \vartheta=2^{\circ}\right)$, the random initial "population" of solution $\varphi(\vartheta)$ was defined. Then, the genetic algorithm iteratively converged to the optimal solutions through the following steps: crossover (reproduction), mutation, fitness function computation (based on Eq. (2)) and elimination of the individuals (solutions) with the least fitness. This led iteratively 

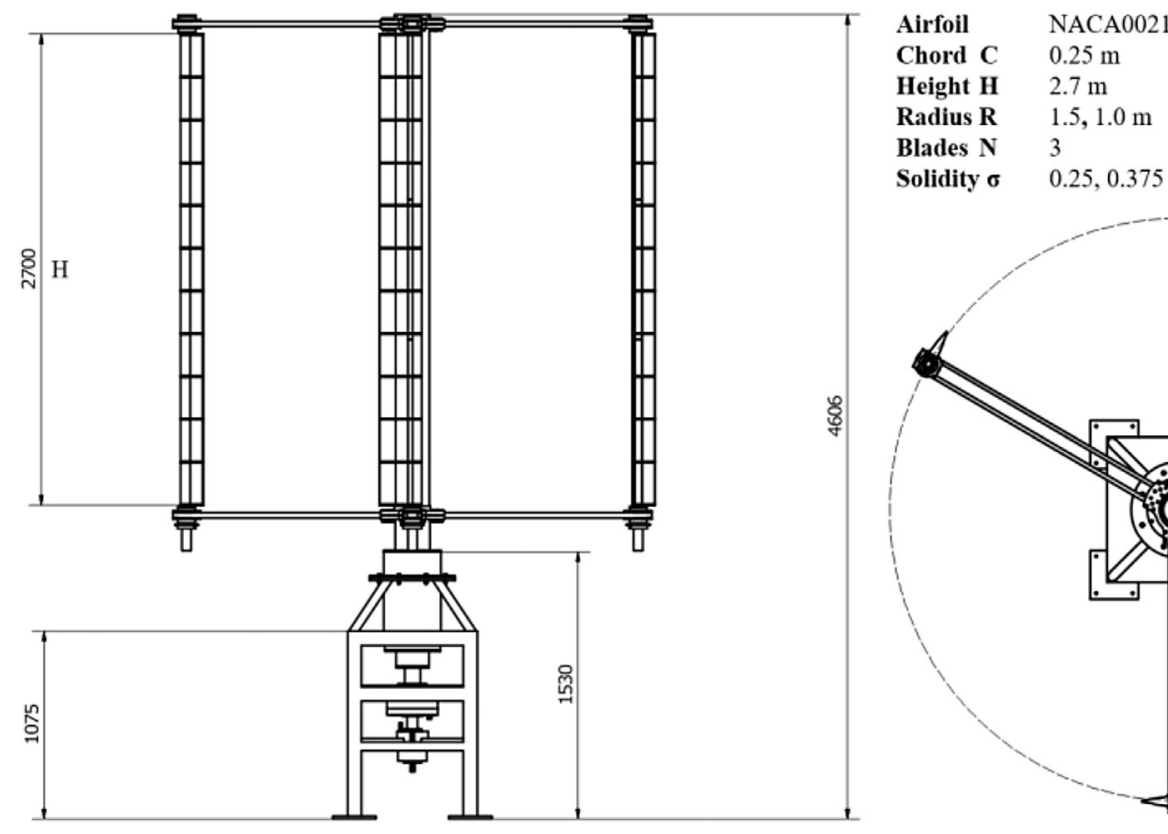

Solidity $\boldsymbol{\sigma} \quad 0.25,0.375$

Fig. 4. PoliMi reference IPC-VAWT for code validation.

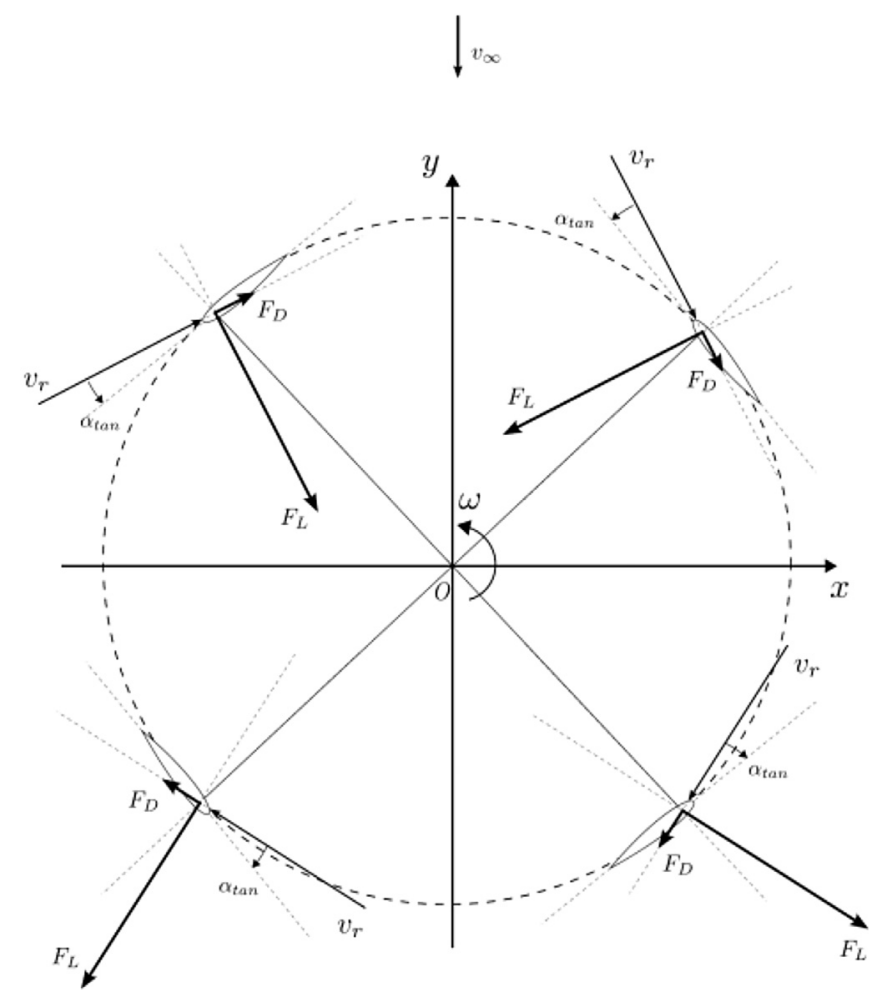

Fig. 5. Conventions adopted for the DMS code implementation.

to selection of the individuals with the optimal fitness $\left(\varphi_{\text {opt }}\right)$, Eq. (3).

$\varphi_{\text {opt }}(\vartheta)=\left[\varphi_{\text {opt }, u}(\vartheta), \varphi_{\text {opt }, d}(\vartheta)\right] \quad \forall \vartheta \in[0, \pi]$

In Figs. 6 and 7 the lift and drag forces on the airfoil, due to the optimal pitch angle $\varphi_{\text {opt }}$, are reported, whereas in the Fig. 8 the lift force spectrum only is shown, representing the greatest

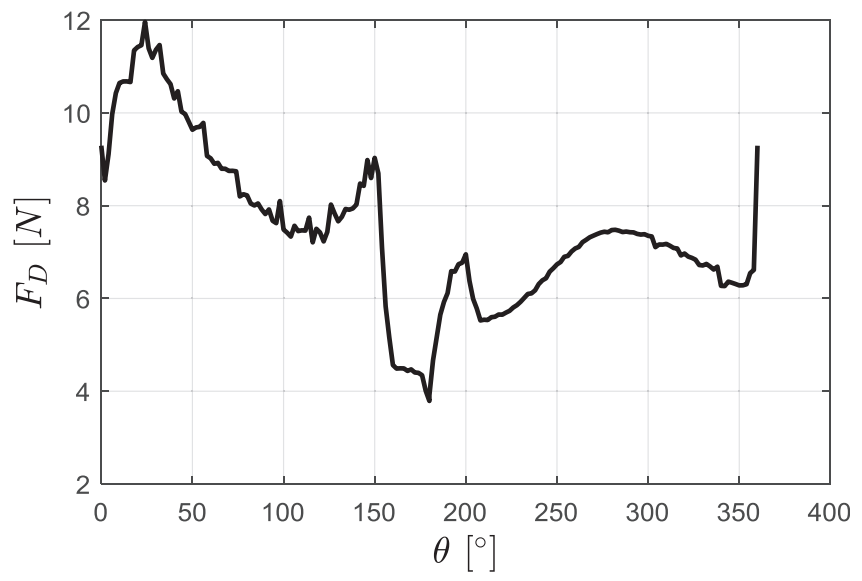

Fig. 6. Drag force on the blade for an optimal pitch angle variation in a revolute.

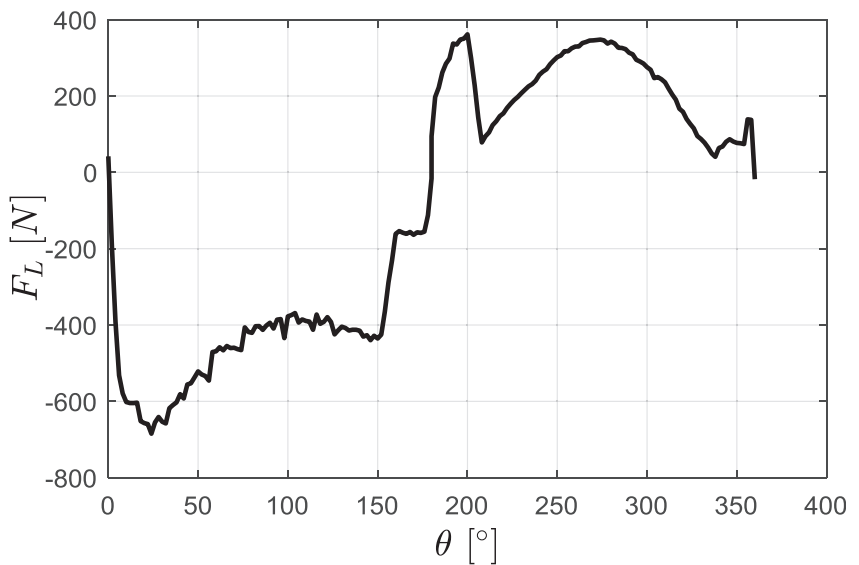

Fig. 7. Lift force on the blade for an optimal pitch angle variation. 


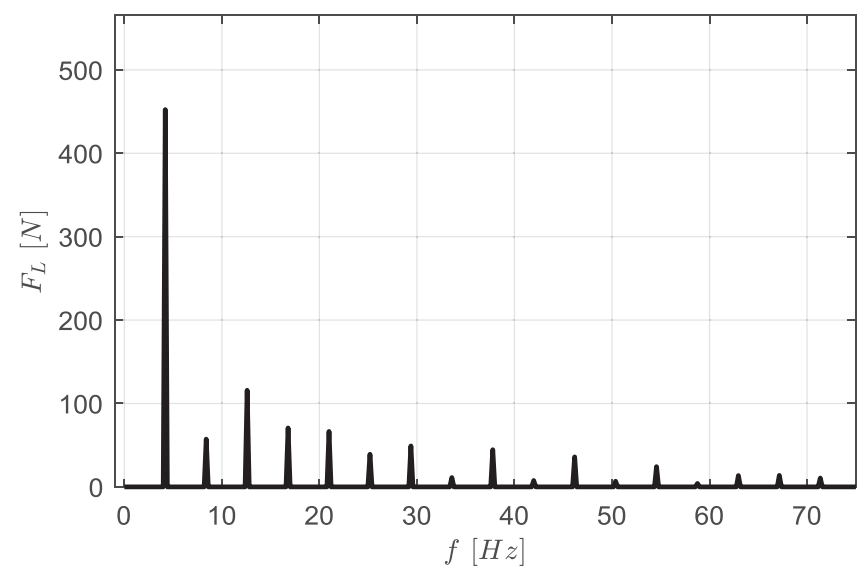

Fig. 8. Lift force spectrum for the design conditions.

aerodynamic contribution. From Fig. 8 it turned out that the most relevant frequency is about at $4.2 \mathrm{~Hz}$, imposing that the blade had the first bending frequency $f_{1}$ at least greater than $2-3$ time the lowest aerodynamic forcing due to pitch variation. In Fig. 9 the comparison of the machine's performance between fixed and optimal pitch configurations is also reported.

\subsection{Blades and structure}

Being the machine presented a reference wind turbine for experimental validation of numerical codes, rather than a scale model of a full-scale prototype, as it is recently being done for floating offshore wind turbine in some European projects [33], the airfoil was chosen among the 4 digits NACA airfoil, to rely on commonly shared profile geometry and aerodynamic polars. Moreover, the choice of the specific airfoil was not only due to aerodynamic considerations but also structural. Therefore, an optimal compromise was found also considering the capability of different airfoils to be fitting an elliptic inner structural beam. The reason why an elliptical shape was chosen was for having a shape coupling to easily transmit the torque from the IPC actuating unit to the blade as well as preventing the adoption of pins or keys for the torque transmission from the IPC motor shaft directly to the blade's carbon fiber.

With reference to Fig. 10 it is evident that the dimension of the ellipsis ( $a$ and $b$ ) and the thickness $s$, have influence on the moment

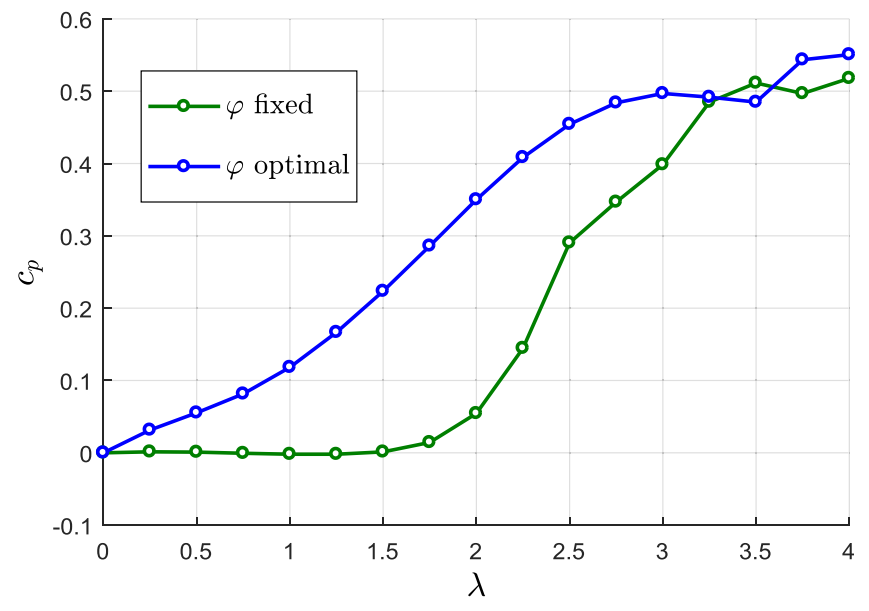

Fig. 9. Power coefficients for fixed and optimal pitch angle. of inertia as well as the mass per unit length of the inner elliptical beam. So that a compromise was to be chosen between increasing the former and reducing the latter. Moreover, it is clear how, chosen the dimension of the beam's section, then the choice of the airfoil can have consequences on the building of the carbon fiber reinforce ribs and their coupling with the elliptic inner beam, in that they have different thickness over chord functions. Defining some geometrical constraints on the ellipsis parameters, which varies among different airfoils, to ensure the shape coupling and to make sure the technological feasibility, the reported genetic algorithm was implemented both considering the minimization of the maximum static displacement, considering safely pin joints at the blades' ends, as equivalent kinematic scheme, as well as the maximization of the first bending frequency. With regard to the former, design conditions were considered for the centrifugal load, as well as the aerodynamic forces. In Figs. 11 and 12 the paretooptimal outputs of the implementation of a genetic algorithm are reported, showing different results for different beam-airfoil coupling. Beside the aerodynamic efficiency, NACA0021 profile turned out to be the optimal in terms of maximum static displacement $w_{m}$ Vs the overall blade's mass $m_{\text {Blade }}$; the combined evaluation with the dynamic optimization (Fig. 12) defined the final geometrical parameters for blades, Fig. 10. The following dimensions (Table 1) were found out of the optimization process, with reference to Fig. 10:

In Fig. 10 also the carbon fiber layup for the elliptic beam is reported, consisting in two inner unidirectional layers and two outer balanced $\left(45^{\circ}\right)$ layers. Regarding the reinforcing ribs, which are made of carbon fiber/composite sandwich, consist in supports for the final layer of balanced carbon fiber, which completes the external cover of the blades (Fig. 10). The final 3D blade structure was verified with a more detailed model Finite Element Method (FEM) (e.g. carbon fiber layup, effective constraints, etc...), see Fig. 13.

In Fig. 13 an overview of the structural design of the other parts of the machine, and the related finite element analysis carried to the check the structural consistency of the design, is reported.

All the structural parts, except for the main support and blades, are made of aluminium 7075-T6, whose properties, characterized by the aluminium lightness and high static and fatigue resistance, are reported in Table 2. The twin braces of each blade are connected to the rotating main shaft from one side, and to the IPC control unit from the other, through flanges with bolt couplings, Fig. 15. FEM analysis has shown that the maximum stresses were well below the yielding limit (Table 2), and they are connected to local stresses due to controlled bolt tightening. Furthermore, the structure support-ing the main shaft (lower left of Fig. 13) is made of steel, with welded transversal braces. The function is also to support the main shaft motor which actuates the main shaft itself (1 in Fig. 14) through a key connected hollow shaft flange (7, in Fig. 14). The structural integrity of this support was verified statically (welding points) and dynamically, more specifically, the first bending fre-quency is circa $50 \mathrm{~Hz}$, so that can be considered as rigid in the operational range.

\subsection{Individual pitch control unit and signals handling}

The design of the IPC unit, reported in Fig. 15, was critical in the sense of combining the functionality of an "on-board" actuation with very limited space at the base of the blade. With reference to Fig. 10, the blade's inner beam is coupled thanks to the elliptical shape to a hollow shaft, referred to as "motor-blade coupling shaft". The actuation to this shaft, and then to the blade, is given through the key of a further intermediate shaft connected to the reducer's one by means of an elastic joint. The motor-reducer unit was 

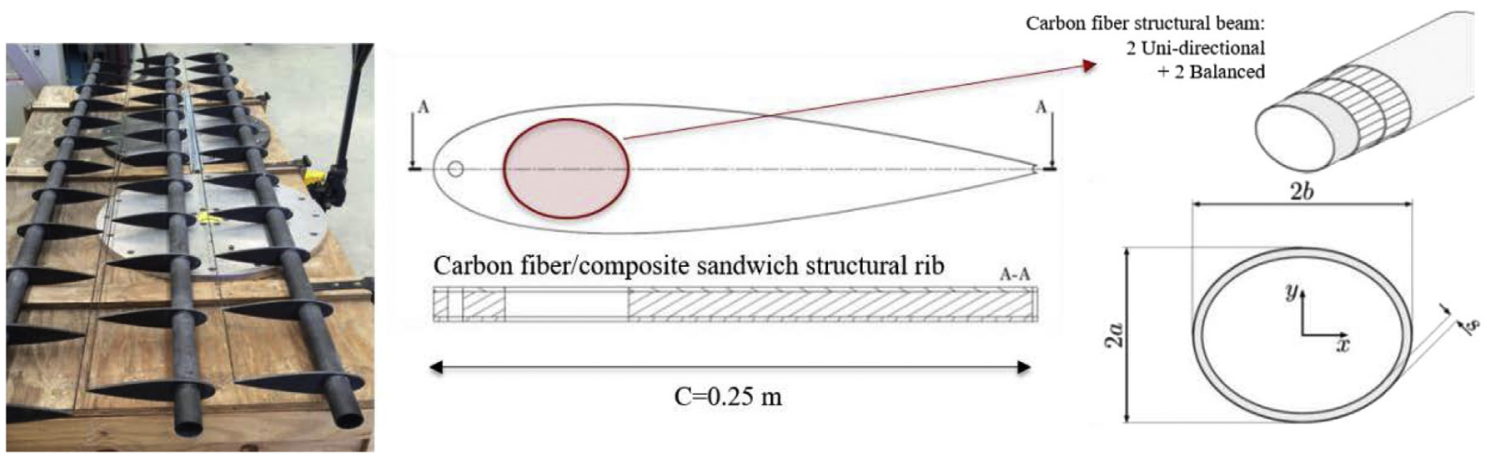

Fig. 10. Carbon fiber internal blade structures.

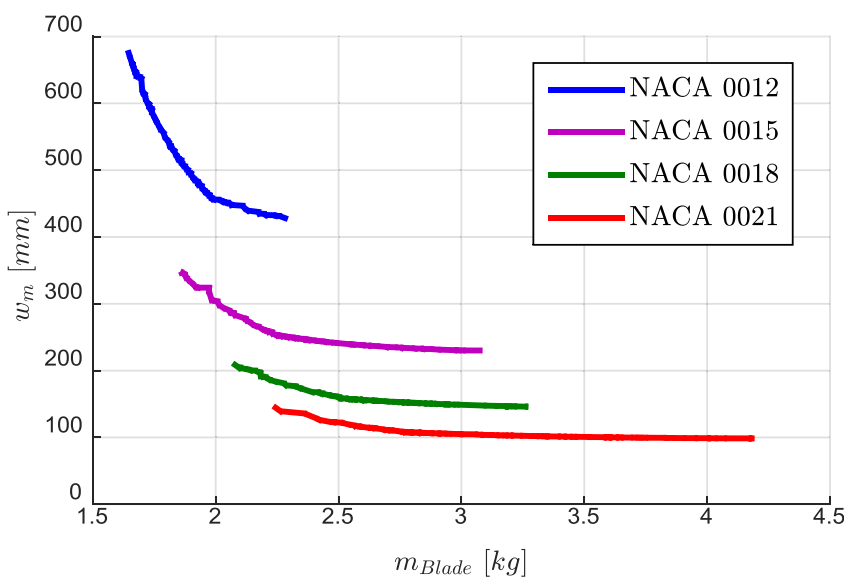

Fig. 11. Aero-structural optimization of the airfoil comparison among different NACA 4 digits airfoils.

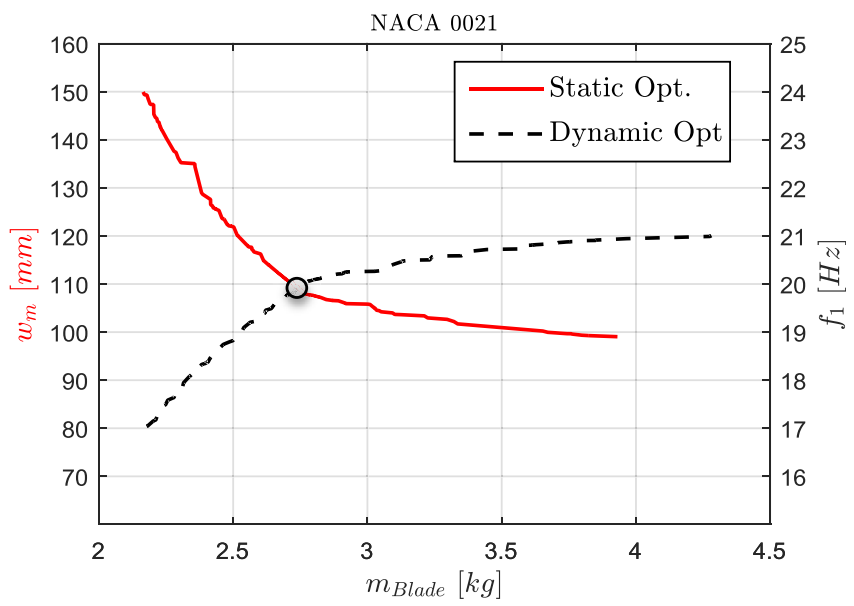

Fig. 12. Static and dynamic combined results for the optimal airfoil choice.

Table 1

Geometrical characteristics of the optimal NACA0021 airfoil.

\begin{tabular}{cccc}
\hline $2 \mathrm{a}(\mathrm{mm})$ & $2 \mathrm{~b}(\mathrm{~mm})$ & $\mathrm{s}(\mathrm{mm})$ & $\mathrm{C}(\mathrm{mm})$ \\
\hline 40 & 50 & 2 & 250 \\
\hline
\end{tabular}

chosen through the "alpha-beta" optimization developed at Politecnico di Milano [35], where alpha and beta are respectively the acceleration factor and the load factor. The choice of the motorreducer to be purchased, among a large amount of different possibilities (performance, technology and cost), is reduced merely to the comparison between these two different parameters, which depend on the elements that the user can find in the data sheets as well as the specific application. Therefore, if alpha is greater than beta the related motor-reducer combination is eligible to be purchased. Therefore, at each time step, the reported genetic algorithm was run coupled to the aerodynamic code [34] (as explained in $\S 4.1)$ to define the best pitch angle as function of the azimuthal angle. This produced the time varying aerodynamic forces in the design operational condition, which were considered as an estimate for the computation of the load factor in the procedure [34], along with the static forcing (centrifugal load) that the rotor need to counteract due to the blade's eccentrical center of mass.

The IPC motors are controlled by miniaturized inverters, which are placed nearby and attached on the twin arms, Fig. 16. The IPC motors' current and velocity control loops are closed on board nearby these inverters, whereas the position loop, in terms of blade's pitch angle is closed by the higher level controller, implementing the IPC-VAWT control laws to be tested, and relying on the feedback signal of an encoder installed at the opposite end (top), as shown in Fig. 16. Therefore, a reference velocity actuation signal is given to the motor based on the position control loop, the former is an analog signal, whereas the latter digital (i.e. encoder's $\mathrm{A} / \mathrm{B} / \mathrm{Z}, \mathrm{A}-/ \mathrm{B}-/ \mathrm{Z}-$ ). Furthermore, beside the control laws aimed at optimizing the aerodynamic performance of the machine, the feedback signal of the encoder is also used as a feedback for the homing operation, which are set to place the airfoil perpendicular to the radius a 0 -azimuthal angle before starting. All the cables, carrying input/output and digital/analog signals, pass through the hollow shaft and are gathered by slip ring rotary contacts and then handled by the higher-level controller. Also, the main shaft motor is hollow, so that it is connected to the main shaft at one end (Fig. 14) and to the slip rings system at the other end. An industrial inverter directly controls this motor, however, the reference in terms of angular speed is given by the high level controller, which can potentially implement speed control laws in addition to IPC control laws at constant angular velocity. As for the IPC motor also for the main shaft one, effective velocity and current (torque) are available to the high-level controller (and for acquisition during wind tunnel tests). Moreover, attached to the motor-shaft connecting flange (i.e. 7 in Fig. 14), an encoder wheel rotates with the main shaft, and two inductive proximitor sensors detect its passage, one for homing purposes and the other for defining the effective position of the shaft, for IPC control target. 


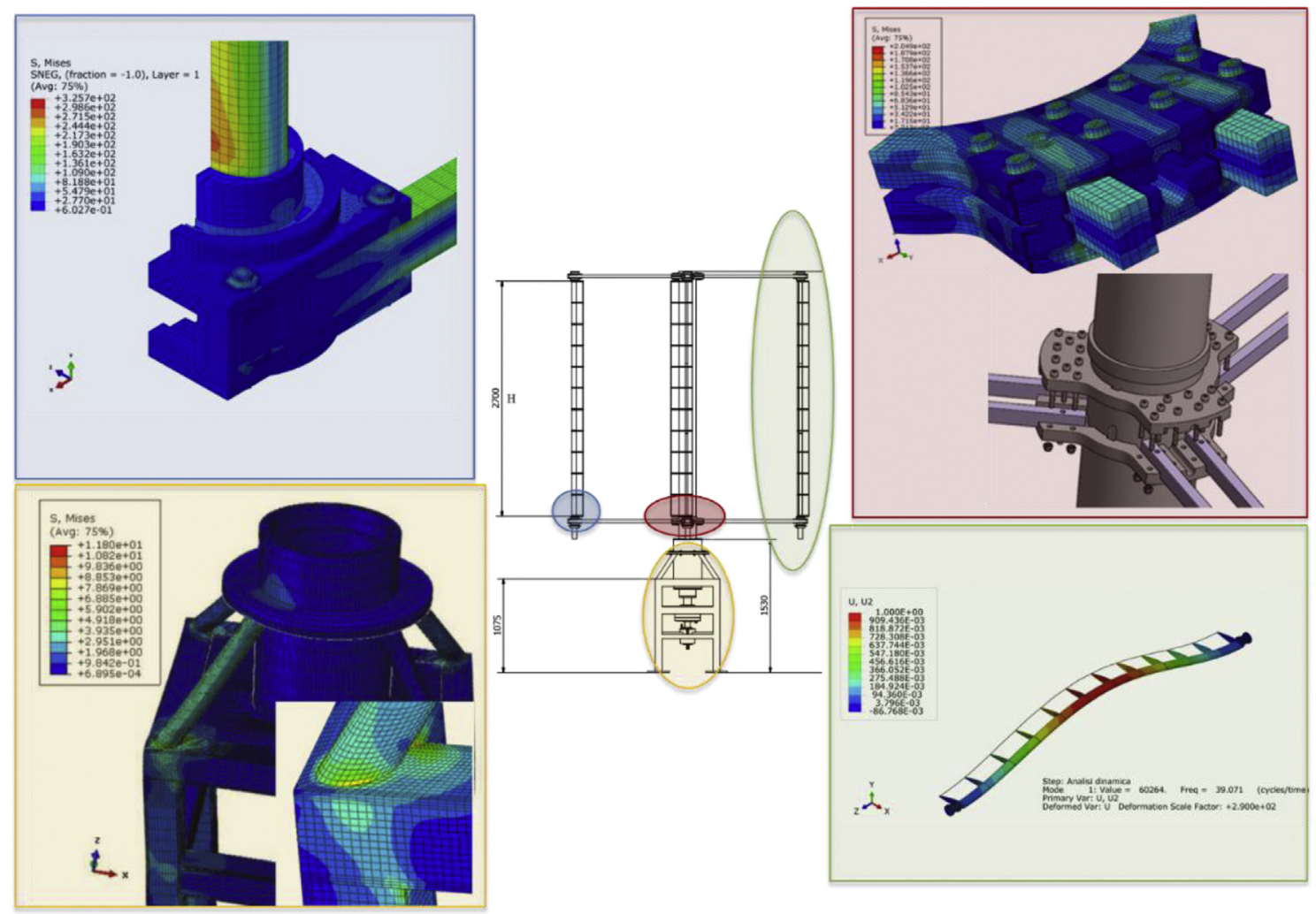

Fig. 13. Overview of the structural design of the reference machine.

Table 2

Mechanical properties of Aluminum 7075-T6.

\begin{tabular}{lllll}
\hline$\rho\left(\mathrm{kg} / \mathrm{m}^{3}\right)$ & $E(\mathrm{MPa})$ & $\sigma_{p 0.2}(\mathrm{MPa})$ & $\sigma_{r}(\mathrm{MPa})$ & $\sigma_{a, \lim }(\mathrm{MPa})$ \\
\hline 2813 & 71100 & 480 & 540 & 150 \\
\hline
\end{tabular}

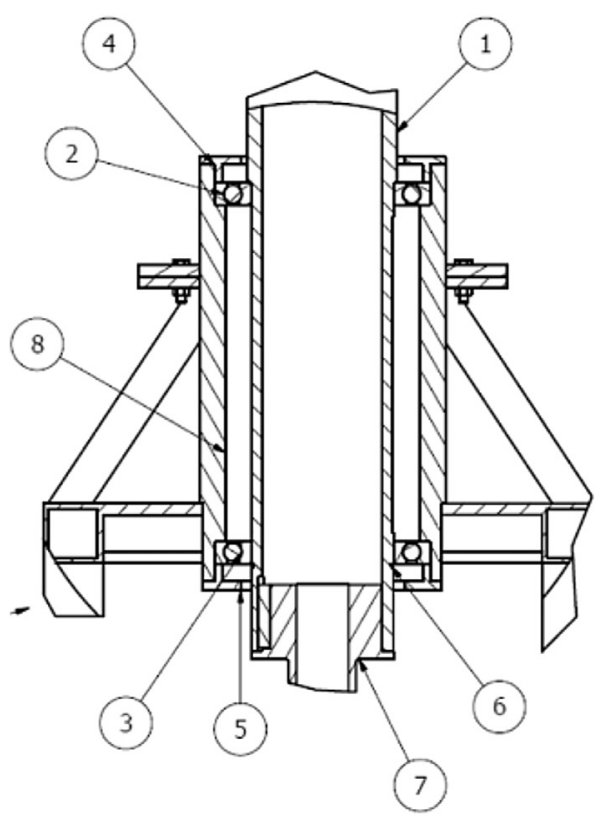

\section{Characterization of the effective capabilities}

The building process terminated with an extensive characterization of the whole machine both in terms of structural dynamics

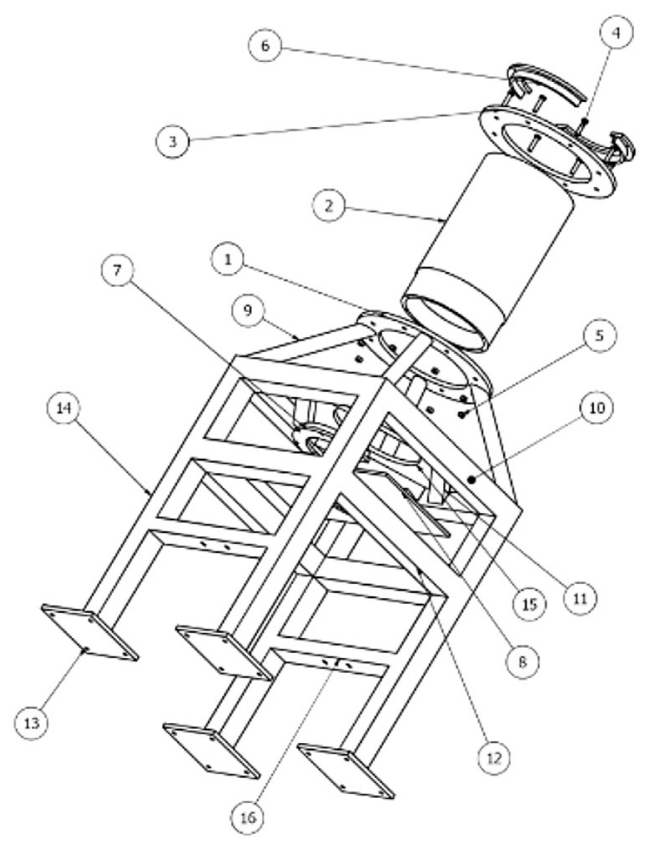

Fig. 14. Overview of the structural design of the reference machine. 


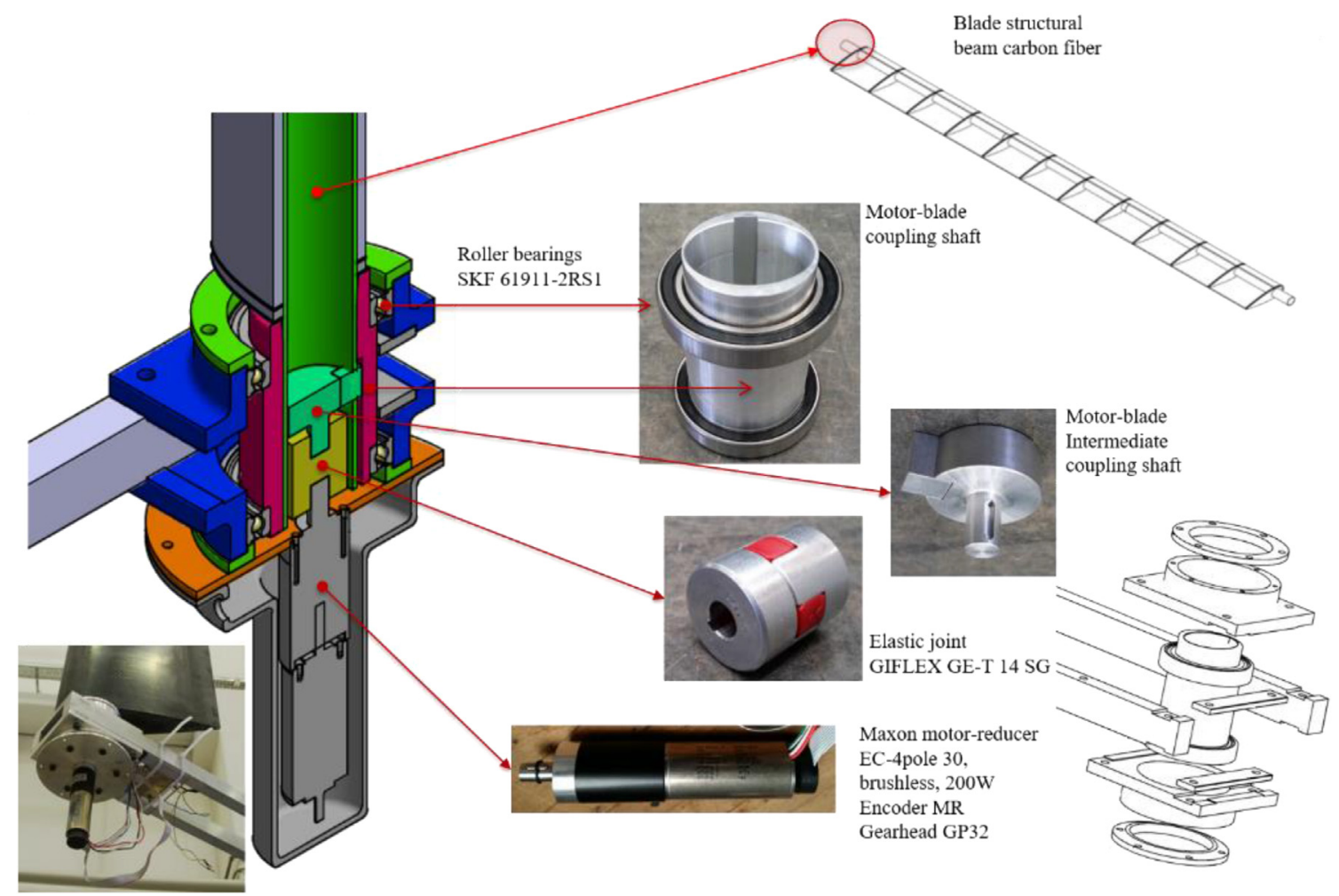

Fig. 15. IPC mechatronic unit of the reference machine.
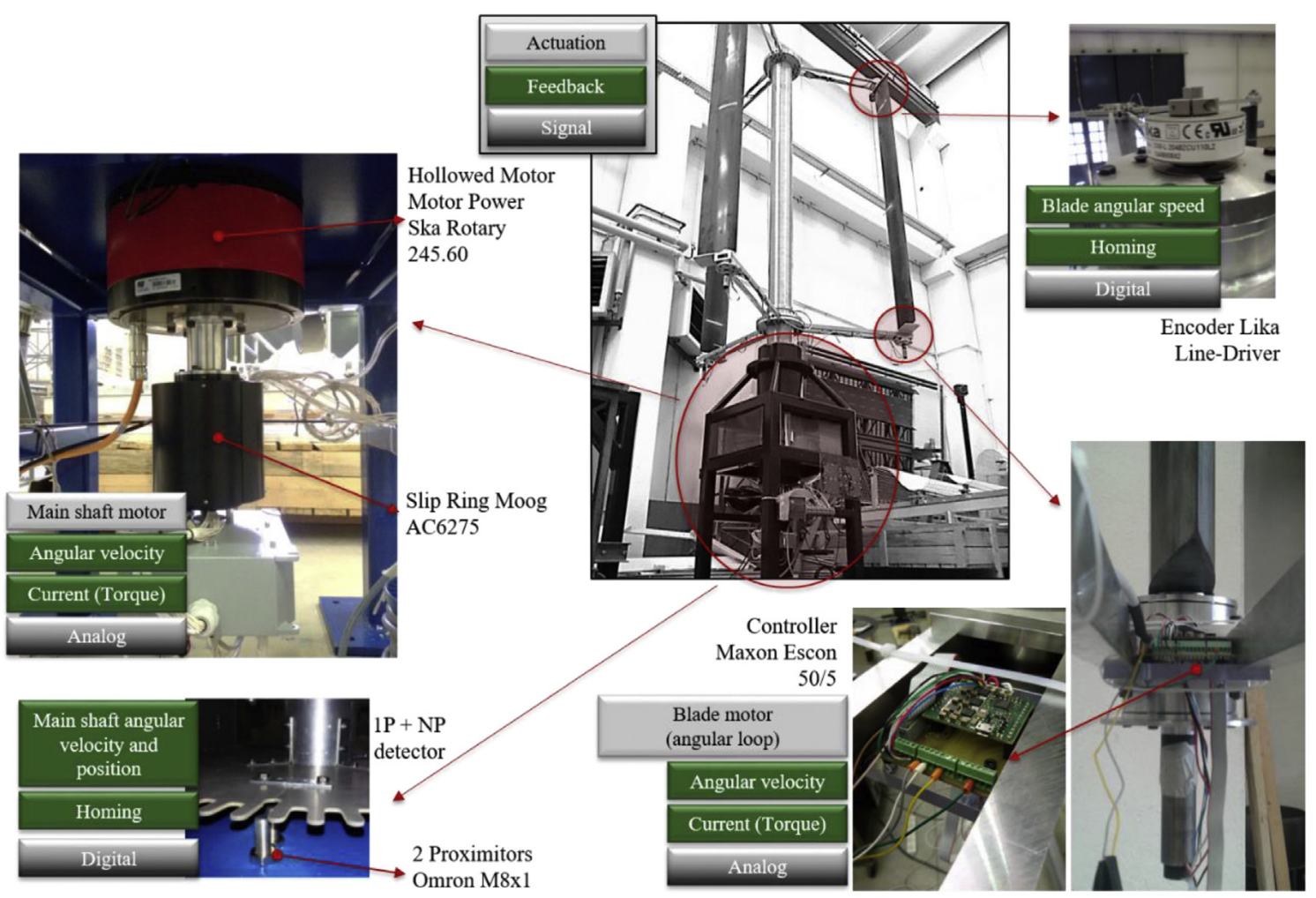

Fig. 16. Overview of the actuations, measurements and signal handlings.

and IPC control bandwidth, with the goal of defining more precisely the actual testing range of the machine under VODCA project.
Therefore, hammer test based modal analysis was conducted with the aim of characterizing the effective natural frequencies of the 

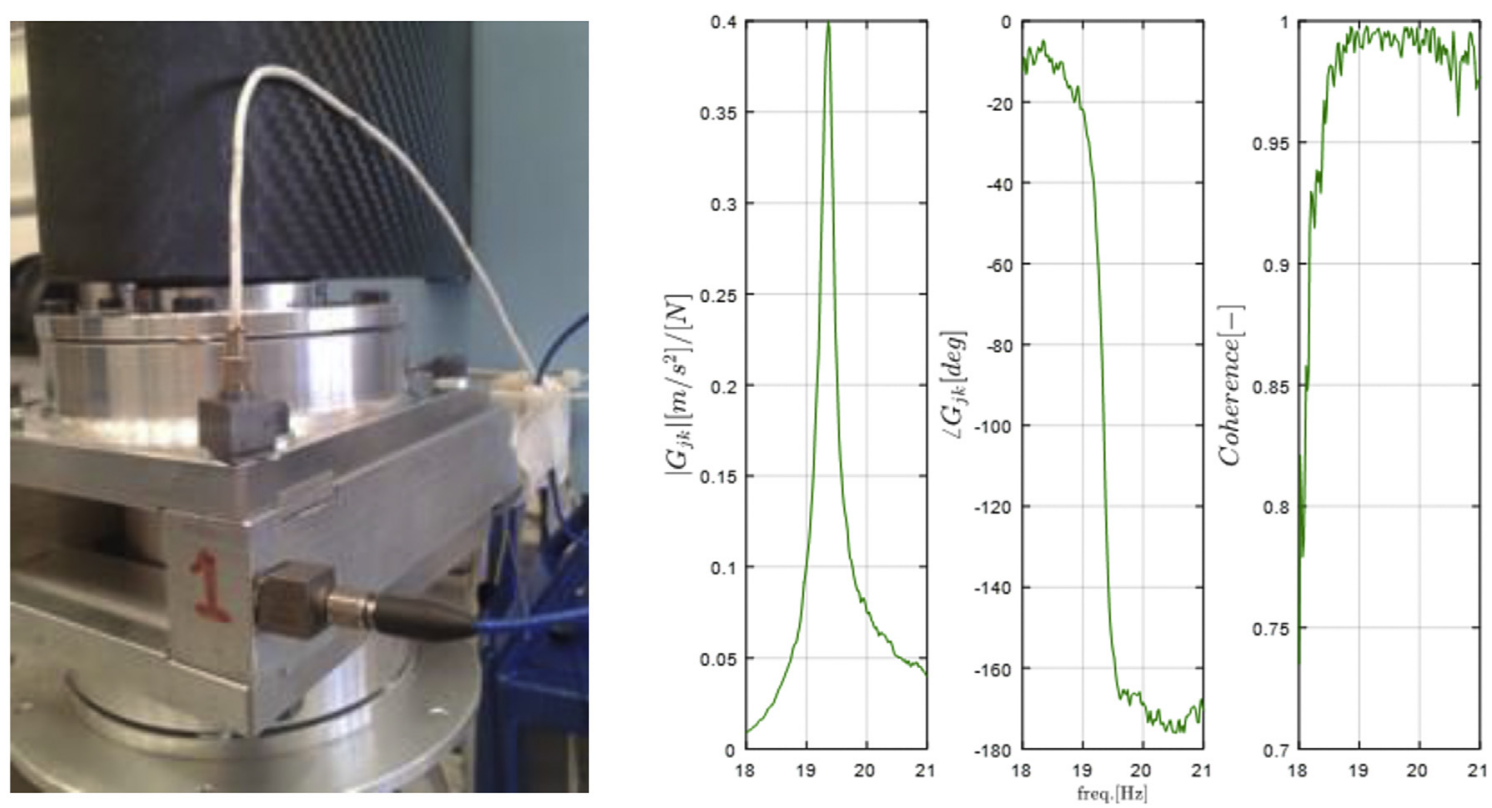

Fig. 17. Modal analysis of the machine.

system. As depicted in Fig. 17, up to 20 accelerometers where placed to detect the structural dynamics of the whole machine in parked condition. The most relevant information is that the first main shaft bending frequency was found to be around $19.5 \mathrm{~Hz}$, lower fre-quency was found for the coupled sub-system armsblade, how-ever the spinning rotor is acting as stiffener for this mode. A lot of different frequencies were found in the system, however, only the ones with high coherence function, theoretically equal to 1 , were considered having physical meaning, in that coherence was found between the input signal (hammer) and the output (accelerom-eter), as common practice in modal analysis [36]. The main shaft bending natural frequency set an upper limit in the main shaft speed, as depicted in Fig. 17. In fact, with the willing to have a ratio between the first bending shaft natural frequency and the 3P greater than 2 times, it can be accepted an angular frequency around $3 \mathrm{~Hz}$. This also to make sure that no resonant vibrations can occur during wind tunnel tests. However, also the IPC bandwidth must be considered, since it is strictly connected to the maximum angular velocity (e.g. the same function of pitch angle Vs azimuthal position, for higher angular speeds, require a wider motor control bandwidth). Therefore, the characterization of the actual control capabilities, in the frequency domain, was necessary. This was carried out providing imposed sine waves for different pitch angles computing the frequency response function between the input angular position and the effective one, looking at the deficit in the magnitude as well as the phase shift of the response. It was found that, considering a possible control law containing up to $3 \mathrm{P}$ of the fundamental harmonic (main shaft rotation) with an amplitude of $5^{\circ}$, a maximum main shaft angular frequency is to be limited to $2.5 \mathrm{~Hz}$, which is consistent with the structural limit above reported.

These considerations are summarized in Fig. 18, where the tip speed ratio $\lambda$ (Eq. (4)):

$\lambda=\frac{\omega R}{V}$

function of the angular speed $\omega$, the radius $R$ and the undisturbed inflow velocity, which governs the aerodynamics of VAWTs, is reported as function of the main shaft rotational frequency $f$. In this

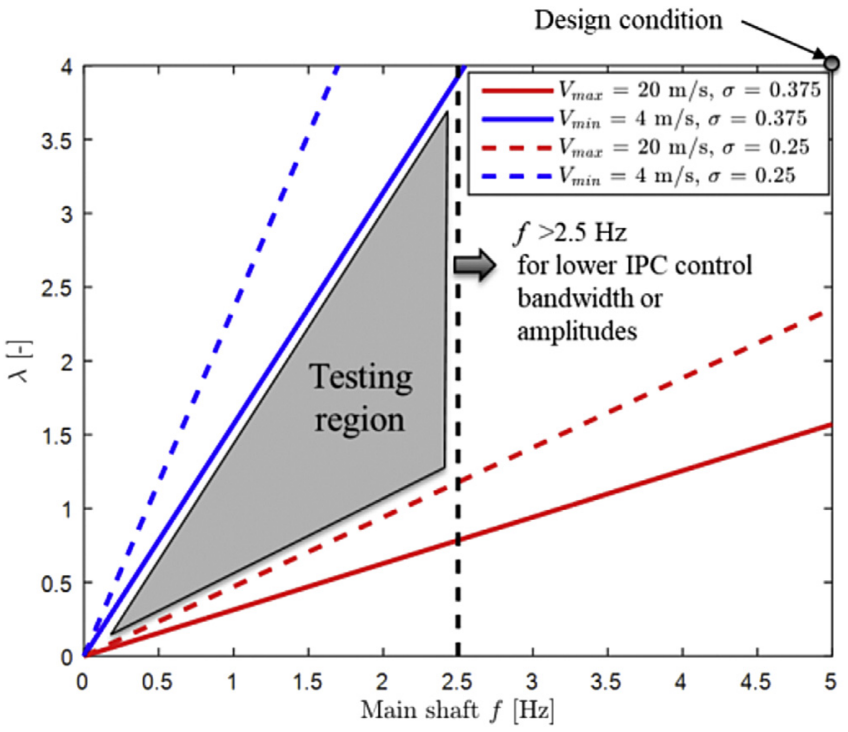

Fig. 18. Testing region for the reference machine.

graph, the testing region is bounded by the above mentioned rotational limit, as well as line linked to the open jet test section operational limits. In fact a range $4-20 \mathrm{~m} / \mathrm{s}$ can be considered reasonable for VODCA project: the lower limit is due to a minimum wind speed required for a good control of the wind flow as well as for having a useful signal/noise ratio in the measurements, whereas the upper bound limit is due to the specific application. The testing region is defined as the intersection between the low and high solidity conditions, even if, as mentioned, VODCA project is probably going to be operating with the higher solidity, which brings about also interesting challenges in the modelling. Higher rotational frequency can be considered, up to the structural limit of $3 \mathrm{~Hz}$, if less aggressive control laws will be implemented either in terms of bandwidth or amplitude of the harmonics. 


\section{Conclusion and ongoing development}

The PoliMi's vertical axis wind turbine with individual pitch control capabilities was designed and built by the authors and its features, openly shared, have been reported and commented. The design approach and choices were also reported and the mechanical and electrical components shown in detail.

The machine is supposed to be a reference VAWT for code validation purposes, under the open data project VODCA, whose aim is to share wind tunnel tests data on the PoliMi IPC-VAWT to participants who wants to validate their own codes. PoliMi will lead the coordination of the project with the goal of providing and sharing insights regarding the complex aerodynamics of VAWTs, through a numerical/experimental approach. Furthermore, IPC control capabilities of the machine will allow to assess the potential improvements due to self-starting and optimal control implementation, also considering the recent interest in adopting IPCVAWTs for Multi -Megawatt floating offshore wind turbines.

\section{Acknowledgements}

The authors would like to thank their alma mater, Politecnico di Milano, for the " $5 \times 1000$ " grant financed to the research group in the name of Professor Belloli, for making possible the design and construction of this reference machine. Furthermore, the help of master students (R. Simonetta, M. Visconti, G. Pirovano, N. Lisignoli, M. Roncoroni and P. Del Pero), over the years, is greatly appreciated.

\section{References}

[1] H.J. Sutherland, D.E. Berg, T.D. Ashwill, A Retrospective of VAWT Technology (SAND2012-0304), Sandia National Laboratories, California, 2012.

[2] Michael Borg, Andrew Shires, Maurizio Collu, Offshore floating vertical axis wind turbines, dynamics modelling state of the art. part I: aerodynamics, Renew. Sustain. Energy Rev. 39 (November 2014) 1214-1225.

[3] Michael Borg, Maurizio Collu, Athanasios Kolios, Offshore floating vertical axis wind turbines, dynamics modelling state of the art. Part II: mooring line and structural dynamics, Renew. Sustain. Energy Rev. 39 (November 2014) 1226-1234.

[4] M. Borg, M. Collu, F.P. Brennan, Offshore floating vertical axis wind turbines: advantages, disadvantages, and dynamics modelling state of the art, in: The International Conference on Marine \& Offshore Renewable Energy (M.O.R.E. 2012), RINA HQ, London, 2012, pp. 26-27. September 2012.

[5] M. Fowler, D. Bull, A. Goupee, A Comparison of Platform Options for Deepwater Floating Offshore Vertical Axis Wind Turbines: an Initial Study, Tech. Rep. SAND2014e16800, Sandia National Laboratories, Aug. 2014

[6] Anders Myhr, Catho Bjerkseter, Anders Ågotnes, Tor A. Nygaard, Levelized cost of energy for offshore floating wind turbines in a life cycle perspective, Renew. Energy 66 (June 2014) 714-728.

[7] Spinfloat concept by Eolfi: https://www.eolfi.com/fr/eolfi-recherchedeveloppement/spinfloat.

[8] InFlow concept by Nenuphar: http://www.nenuphar-wind.com/fr/.

[9] Uwe S. Paulsen, Helge A. Madsen, Knud A. Kragh, Per H. Nielsen, Ismet Baran, Jesper Hattel, Ewen Ritchie, Krisztina Leban, Harald Svendsen, Petter A. Berthelsen, DeepWind-from idea to $5 \mathrm{MW}$ concept, Energy Procedia 53 (2014) 23-33.

[10] J.F. Manwell, J.G. McGowan, A.L. Rogers, Wind Energy Explained: Theory, Design and Application.

[11] I. Paraschivoiu, Wind Turbine Design with Emphasis on Darrieus Concept, Polytechnic International Press, Montreal, Canada, 2002.

[12] D. Marten, A. Bianchini, G. Pechlivanoglou, F. Balduzzi, C.N. Nayeri, G. Ferrara, C.O. Paschereit, L. Ferrari, Effects of Airfoil's polar data in the stall region on the estimation of Darrieus wind turbine performance, J. Eng. Gas Turbines Power 139 (2) (2017), 022606.

[13] A. Bianchini, F. Balduzzi, J.M. Rainbird, J. Peiro, J.M.R. Graham, G. Ferrara, L. Ferrari, An experimental and numerical assessment of airfoil polars for use in Darrieus wind Turbines-Part II: post-stall data extrapolation methods,
J. Eng. Gas Turbines Power 138 (3) (2016), A2.

I. B.K. Kirke, Evaluation of Self-starting Vertical Axis Wind Turbines for Stand-alone Applications, Ph.D. thesis, Griffith University, Gold Coast, Australia, 1998.

[15] I.S. Hwang, S.Y. Min, I.O. Jeong, Y.H. Lee, S.J. Kim, Efficiency improvement of a new vertical axis wind turbine by individual active control of blade motion, in: Smart Structures and Materials 2006: Smart Structures and Integrated Systems, Vol. 6173 of Proceedings of SPIE, March 2006, pp. 316-323. San Diego, Calif, USA.

[16] L.-X. Zhang, Y.-B. Liang, X.-H. Liu, J. Guo, Effect of blade pitch angle on aerodynamic performance of straight-bladed vertical axis wind turbine, J. Cent. South Univ. 21 (4) (2014) 1417-1427.

[17] G.J.M. Darrieus, Turbine having its rotating shaft transverse to the flow current. US Patent no. 1.835.018, 1931.

[18] N.C.K. Pawsey, Development and Evaluation of Passive Variable Pitch VerticalAxis Wind Turbines, Ph.D. thesis, The University of New SouthWales, Sydney, Australia, November 2002.

[19] M. Elkhoury, T. Kiwata, E. Aoun, Experimental and numerical investigation of a three-dimensional vertical-axis wind turbine with variable-pitch, J. Wind Eng. Ind. Aerod. 139 (April 2015) 111-123.

[20] A. Palash Jain, Abhishek, Performance prediction and fundamental understanding of small scale vertical axis wind turbine with variable amplitude blade pitching, Renew. Energy 97 (November 2016) 97-113.

[21] M. Benedict, V. Lakshminarayan, J. Pino, I. Chopra, Fundamental understanding of the physics of a small-scale vertical axis wind turbine with dynamic blade pitching: an experimental and computational approach, in: 54th AIAA/ ASME/ASCE/AHS/ASC Structures, Structural Dynamics, and Materials Conference, 2013.

[22] L. Zhang, Y. Pei, Y. Liang, F. Zhang, Y. Wang, J. Meng, H. Wang, Design and implementation of straight-bladed vertical axis wind turbine with collective pitch control, in: 2015 IEEE International Conference on Mechatronics and Automation, ICMA 2015, 2015, pp. 1258-1263 art. no. 7237666.

[23] Y.-B. Liang, L.-X. Zhang, E.-X. Li, F.-Y. Zhang, Blade pitch control of straightbladed vertical axis wind turbine, J. Cent. South Univ. 23 (5) (2016) 1106-1114

[24] C.S. Ferreira, H.A. Madsen, M. Barone, B. Roscher, P. Deglaire, I. Arduin, Comparison of aerodynamic models for vertical axis wind turbines, J. Phys. Conf. Ser. 524 (1) (2014), 012125.

[25] P. Passon, M. Kühn, S. Butterfield, J. Jonkman, T. Camp, T.J. Larsen, OC3Benchmark exercise of aero-elastic offshore wind turbine codes, J. Phys. Conf. Ser. 75 (1) (2007), 012071.

[26] A. Robertson, Jonkman, ..., Offshore code comparison collaboration continuation within IEA wind task 30: phase II results regarding a floating semisubmersible wind system, in: Proceedings of the International Conference on Offshore Mechanics and Arctic Engineering - OMAE, 2014.

[27] A.N. Robertson, F.F. Wendt, ..., OC5 project Phase I: validation of hydrodynamic loading on a fixed cylinder, in: Proceedings of the International Offshore and Polar Engineering Conference, 2015-January, 2015, pp. 471-480.

[28] VODCA project. www.vodca.polimi.it.

[29] I. Bayati, M. Belloli, A. Facchinetti, S. Giappino, Wind tunnel tests on floating offshore wind turbines: a proposal for hardware-in-the-loop approach to validate numerical codes, Wind Eng. 37 (6) (2013) 557-568.

[30] I. Bayati, M. Belloli, L. Bernini, A. Zasso, Wind tunnel validation of AeroDyn within LIFES50+ project: imposed Surge and Pitch tests, J. Phys. Conf. Ser. Sci. Mak. Torque Wind 753 (9) (2016), http://dx.doi.org/10.1088/1742-6596/753/ 9/092001.

[31] L. Battisti, E. Benini, A. Brighenti, M. Raciti Castelli, S. Dell'Anna, V. Dossena, G. Persico, U. Schmidt Paulsen, T.F. Pedersen, Wind tunnel testing of the DeepWind demonstrator in design and tilted operating conditions, Energy 111 (2016) 484-497.

[32] M. Biava, G. Campanardi, G. Gibertini, D. Grassi, L. Vigevano, A. Zanotti, Wind tunnel open section characterization for rotorcraft tests, 38th European Rotorcraft Forum, September 4-7 2012, Amsterdam, The Netherlands.

[33] I. Bayati, M. Belloli, L. Bernini, R. Mikkelsen, A. Zasso, On the aero-elastic design of the DTU $10 \mathrm{MW}$ wind turbine blade for the LIFES50+ wind tunne scale model, J. Phys. Conf. Ser. Sci. Of Mak. Torque Wind 753 (2) (2016), http:// dx.doi.org/10.1088/1742-6596/753/2/022028.

[34] Ion Paraschivoiu, Francois Delclaux, Double Multiple streamtube model with recent improvements, J. Energy 7 (3) (1983) 250-255.

[35] H. Giberti, S. Cinquemani, G. Legnani, A practical approach to the selection of the motor-reducer unit in electric drive systems, Mech. Base. Des. Struct. Mach. 39 (3) (2011) 303-319.

[36] M. Belloli, I. Bayati, S. Giappino, S. Muggiasca, L. Rosa, Modal parameters identification and monitoring of two arches, MATEC Web Conf. 24 (2015), 04002. 